\title{
International Medical Teams of the Japan Medical Association: A Framework for Foreign Medical Teams
}

\author{
Takashi Nagata, MD; Sumito Yoshida; Manabu Hasegawa, MD; Mayo Ojino; \\ Shinichi Murata; Masami Ishii, MD'
}

T he Japan Medical Association (JMA) trains and coordinates medical teams, known as Japan Medical Association Teams (JMATs), to respond in the event of a disaster or other largescale medical emergency. ${ }^{1}$ In response to the Great East Japan Earthquake, the JMA, which comprises 160,000 members, deployed JMATs to the 4 prefectures with the most devastating conditions: Iwate, Miyagi, Fukushima, and Ibaraki. ${ }^{1}$

After the Great East Japan Earthquake in 2011, the JMA, as the professional society of Japanese physicians, recognized the importance of incorporating foreign medical teams (FMTs) into its large-scale disaster response efforts. ${ }^{2}$ The JMA has developed international medical teams of the JMA, or iJMAT, as a new framework to accept FMTs to provide medical care in the event of major disasters, particularly the predicted Tokyo metropolitan or South Sea Thrust mega-earthquakes. ${ }^{3}$ The main aim of the iJMAT program is to secure the quality of care provided and certification of physicians' qualifications to meet the needs of disaster-affected areas.

Over 30 nations offered medical assistance to the Japanese government following the Great East Japan Earthquake, and only 4 FMTs from Israel, Jordan, Thailand, and Philippines, could be accepted. The Ministry of Foreign Affairs, Japan, proposed "The scheme for medical assistance from abroad," and the following 6 criteria had to be fulfilled before accepting assistance ${ }^{2}$ :

1. FMTs should be self-contained (capable of providing the necessary drugs, medical equipment, food, water, fuel, etc, on their own).

2. FMTs should send enough interpreters to meet the need.

3. FMTs should also send Japanese physicians with experience in international cooperation.

4. The duration should be 2 to 4 weeks (but caseby-case).

5. A local disaster management headquarters should manage their activities.
6. The government should cooperate on the smooth clearance of drugs and test equipment through customs.

To validate the concept of $i$ JMAT, the JMA proposes that 2 major medical declarations/guidelines, the World Medical Association Declaration of Montevideo on Disaster Preparedness and Medical Response and the Sphere Project, should be followed. The World Medical Association Declaration of Montevideo, ${ }^{4}$ adopted in October 2011, calls upon its members "to promote a standard competency set to ensure consistency among disaster training programs for physicians across all specialties." Health care workers joining the iJMAT should have their own specialties and complete disaster medicine training in advance. The Sphere Project was initiated in 1997 by a group of nongovernmental organizations and the Red Cross and Red Crescent Movement to develop a set of universal, minimum standards in core areas of humanitarian responses, resulting in creation of the Sphere Handbook. ${ }^{5}$

Based on lessons learned through successful deployment of JMATs and difficulties in accepting FMTs following the Great East Japan Earthquake, the concept of international medical teams in the JMAT was proposed by the JMA. The predicted Tokyo metropolitan mega-earthquake and South Sea Thrust mega-earthquake require advance planning in disaster medicine. If such events occur, FMTs are expected to participate in the disaster response as iJMATs.

\section{About the Authors}

Japan Medical Association Research Institute, Tokyo, Japan (Drs Nagata and Ishii, Mr Yoshida, Ms Ojino), Kyushu University, Faculty of Medical Sciences, Department of Advanced Medical Initiative, Fukuoka-city, Japan (Dr Nagata), Department of Public Health, Shimonoseki-city, Yamaguchi, Japan (Dr Hasegawa), Kaneko $\mathfrak{E}$ Iwamatsu Attorney at Law, Tokyo, Japan (Mr Murata), Japan Medical Association, Tokyo, Japan (Dr Ishii).

Correspondence and reprint requests to Takashi Nagata, MD, Japan Medical Association Research Institute, 2-28-16, Honkomagome, Bunkyo-ku, 113-8621, Tokyo, Japan (nagata.takashi@kyudai.jp).

Published online: October 1, 2015. 


\section{REFERENCES}

1. Ishii M, Nagata T. The Japan Medical Association's disaster preparedness: lessons from the Great East Japan Earthquake and Tsunami. Disaster Med Public Health Prep. 2013;7(5):507-512.

2. Ministry of Foreign Affairs, Government of Japan. Information relating to the recovery from the Great East Japan Earthquake: emergency assistance from other nations and regions in the world. http://www.mofa.go.jp/mofaj/ saigai/kaigai-iryo-shien.html. Accessed March 29, 2015.
3. Cabinet Office, Government of Japan. The estimated damage of the Tokyo Metropolitan mega-earthquake. 2013. http://www.bousai.go.jp/ jishin/syuto/taisaku_wg/index.html. Accessed March 29, 2015.

4. World Medical Association Declaration of Montevideo on Disaster Preparedness and Medical Response. World Med J. 2011; 57(6):227.

5. The Sphere Project. Humanitarian Charter and Minimum Standards in Humanitarian Response. http://www.spherehandbook.org/en/the-humanitarian-charter/. Accessed March 29, 2015

\title{
Comments on "Evaluation Indexes of Military Hospitals From the Experts' Perspective: A Qualitative Study"
}

\author{
Mohammadkarim Bahadori, PhD; Ehsan Teymourzadeh, PhD; Ramin Ravangard, PhD; Seyed Mojtaba \\ Hosseini, PhD
}

W e recently read an article entitled "Evaluation Indexes of Military Hospitals From the Experts' Perspective: A Qualitative Study" in your prestigious journal owing to our interest in qualitative studies. ${ }^{1}$ Although this article is an innovative one in terms of its topic, it seems that some issues should be further taken into consideration. The authors of this article have stated that quality is not improved by performing accreditation, while according to the results of another study, performing accreditation can improve the quality. ${ }^{2}$ The authors mentioned that the available models of performance evaluation such as accreditation are not perfect and complete for evaluating hospitals' performance. However, accreditation has been considered a useful tool for evaluating the managerial and organizational performance of a hospital and does not only evaluate the quality of medical practices. ${ }^{3}$

Some items in this article are unclear, as follows. It is unclear which approach to content analysis was used. Overall, content analysis has 3 approaches: conventional, directional, and summative. However, as mentioned above, the type of content analysis, as well as the analysis unit, meaning unit, and condensation are unclear in this study. Regardless of the names of the authors, it is not clear in which country this study was conducted. The characteristics of the people who were interviewed are not clear, although the base of a qualitative study is the characteristics of the study population. ${ }^{4}$ Furthermore, in the Abstract, it was mentioned that version 11 of the software was used; however, in the Methods, the version of the software is stated as 10; the validity of the code is unclear. Also, "290 primary concepts" is wrong; the proper form is "290 meaning units." "Crisis" has not been defined clearly. The strategy of coding is ambiguous. Have the researchers used open coding or axial coding?

The method of qualitative studies is more an inductive one and moves from the more specific to the more general. That is, the inductive method moves from specific observations to broader generalizations and theories, and there should be a semantic relationship between the themes and subthemes.
However, in this study, there is no semantic relationship between the themes of services, treatment, and passive defense.

The authors have not provided any definition of the military hospital. In Iran, military hospitals are mostly in urban areas and provide services similar to those provided by other civilian hospitals. The only differences between these 2 kinds of hospitals are that in the military hospitals, the military personnel and their families have higher priorities, and persons covered by the armed forces medical insurance do not pay for receiving services. Military hospitals, like other hospitals, are also accredited by the Ministry of Health and Medical Education on the basis of compliance with national standards.

The aim of the study is unclear. It is not clear if the researchers sought to develop some indicators for evaluating military hospitals in emergency situations or if they wanted to provide new models and indicators for evaluating military hospitals in Iran. In fact, no specific indicators or criteria are provided for evaluating military hospitals in Iran. According to which scientific references and documents do the authors of this article state that the role of military hospitals is more important than that of civilian hospitals in emergency situations? All that was mentioned in the coding and provided in the themes and subthemes was that integrated system of crisis management are now available for military and civilian hospitals in emergency situations. It seems better to replace the evaluation indicators with evaluation dimensions. Finally, there is no discussion of the findings, and it seems that the findings are not generalizable even for Iran, and that the evaluation of military hospitals cannot be carried out based on what is stated in this article. ${ }^{5}$

\section{About the Authors}

Health Management Research Center, Baqiyatallah University of Medical Sciences, Tehran, Iran (Dr Bahadori), Health Management Research Center, Baqiyatallah University of Medical Sciences, Tehran, Iran (Dr Teymourzadeh), Department of Health Services Management, School of Management and Medical Information Sciences, Shiraz University of Medical Sciences, 
Shiraz, Iran (Dr Ravangard), Department of Health Services Management, Tehran North Branch, Islamic Azad University, Tehran, Iran (Dr Hosseini).

Correspondence and reprint requests to Mohammadkarim Bahadori, PhD, Manager of Health Policy Department, Health Management Research Center, Baqiyatallah University of Medical Sciences, Tehran, Iran (e-mail: bahadorihealth@gmail.com).

Published online: September 14, 2015.

\section{REFERENCES}

1. Ameryoun A, Haghdoost AA, Zaboli R, et al. Evaluation indexes of military hospitals from the experts' perspective: a qualitative study.

Disaster Med Public Health Prep. 2015;9:409-414.
2. Devkaran S, O'Farrell PN. The impact of hospital accreditation on quality measures: an interrupted time series analysis. $\mathrm{BMC}$ Health Serv Res. 2015;15(1):137 http://dx.doi.org/10.1186/s12913-0150784-5.

3. Pomey M, Francois P, Contandriopoulos A, et al. Paradoxes of French accreditation. Qual Saf Health Care. 2005;14(1):51-55 http://dx.doi.org/ 10.1136/qshc.2004.011510.

4. Bahadori M. Comments on factors influencing medical service quality. Iran J Public Health. 2014:43(9):1314-1315.

5. Bahadori M, Ravangard R, Yaghoubi M, et al. Assessing the service quality of Iran military hospitals: Joint Commission International standards and Analytic Hierarchy Process (AHP) technique. J Educ Health Promot. 2014; Aug 28;3:98. doi: 10.4103/ 2277-9531.139680.

doi:10.1017/dmp.2015.174

\title{
Comments on "Evaluation Indexes of Military Hospitals From the Experts' Perspective: A Qualitative Study"—ERRATUM
}

\author{
Mohammadkarim Bahadori; Ehsan Teymourzadeh; Ramin Ravangard \\ Seyed Mojtaba Hosseini
}

doi:10.1017/dmp.2015.106, Published by Cambridge University Press, 14 September 2015.

I

$\mathrm{n}$ the Letter to the Editor titled "Comments on 'Evaluation Indexes of Military Hospitals From the Experts'

Perspective: A Qualitative Study"' (originally published online September 14, 2015) the fourth reference was not complete. The complete and correct form is:

Bahadori M, Ravangard R. Comments on factors influencing medical service quality. Iran J Public Health. 2014;43(9): $1314-1315$

\section{REFERENCE}

Bahadori M, Teymourzadeh E, Ravangard R, Hosseini SM. Comments on "Evaluation Indexes of Military Hospitals From the Experts' Perspective: A Qualitative Study". Disaster Medicine and Public Health Preparedness. 2015. doi: 10.1017/dmp.2015.106. 